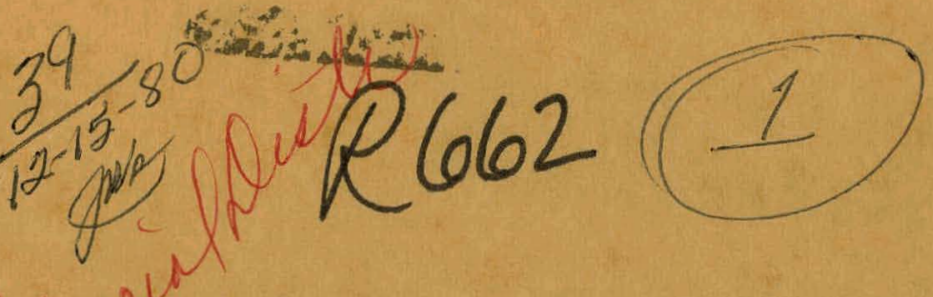

WAPD-TMे-1472 DOE RESEARCH AND DEVELOPMENT REPORT

\title{
A THERMOMECHANICAL THEORY OF MATERIALS UNDERGOING LARGE ELASTIC AND VISCOPLASTIC DEFORMATION
}

(AWBA Development Program)

S. E. MARTIN

J. B. NEWMAN

November 1980

Contract No. DE-AC11-76PNOOO14 


\section{DISCLAIMER}

This report was prepared as an account of work sponsored by an agency of the United States Government. Neither the United States Government nor any agency Thereof, nor any of their employees, makes any warranty, express or implied, or assumes any legal liability or responsibility for the accuracy, completeness, or usefulness of any information, apparatus, product, or process disclosed, or represents that its use would not infringe privately owned rights. Reference herein to any specific commercial product, process, or service by trade name, trademark, manufacturer, or otherwise does not necessarily constitute or imply its endorsement, recommendation, or favoring by the United States Government or any agency thereof. The views and opinions of authors expressed herein do not necessarily state or reflect those of the United States Government or any agency thereof. 


\section{DISCLAIMER}

Portions of this document may be illegible in electronic image products. Images are produced from the best available original document. 
A THERMOMECHANICAL THEORY OF MATERIALS UNDERGOING LARGE ELASTIC AND VISCOPLASTIC DEFORMATION

(AWBA Development Program)

S. E. Martin

J. B. Newman

Contract No. DE-ACI1-76-PN00014

November 1980

Printed in the United States of America Available from the

National Technical Information Service

U. S. Department of Commerce 5285 Port Royal Road Springfield, Virginia 22151

NOTE

This document is an interim memorandum prepared primarily for internal reference and does not represent a final expression of the opinion of Westinghouse. When this memorandum is distributed externally, it is with the express understanding that Westinghouse makes no representation as to completeness, accuracy, or usability of information contained herein.

Operated for the U.S. Department of Energy

by WESTINGHOUSE ELECTRIC CORPORATION 
WAPD $-19+1472$

NOTICE

Th1s report was prepared as an account of work sponsored by the United States Government. Neither the United States, nor the United States Department of Energy, nor any of their employees, nor any of their contractors, subcon-. tractors, or their employees, makes any warranty, express or implied, or assumes any legal liability or responsibility for the accuracy, completeness or usefulness of any information, apparatus, product or process disclosed, or represents that its use would not infringe privately owned rights. 
FOREWORD

The Shippingport Atomic Power Station located in Shippingport, Pennsylvania was the flrst large-scale, central-station nuclear power plant in the United States and the first, plent of such size in the world operated solely to produce electric power. This program iwas started in 1953 to confirm the practicel application of nuclear power for large-scale electric power generation. It has provided much of the |technology beling used for design and operation of the comercial, central-station nuclear power plants now in use.

Subsequent to development and successful operation of the Pressurized Water Reactor in the Atomic Energy Commission (now Department of Energy, DOE) owned reactor plant at the Shippingport Atomic Power Station, the Atomic Energy Comission in 1965 undertook a research and development program to design and build a Light Water Breeder Reactor core for operation in the Shippingport Station.

The objective of the Ifght Water Breeder Reactior (LWBR) program has been to develop a technology that would significantly improve the utilization of the nation's nuclear fuel resources employing the well-established water reactor technology. To achleve this objective, work has been directed toward analysis, design, component tests, and fabrication of a water-cooled, thorium oxideuranium oxdide fuel cycle breeder reactor for installation and operation at the Shippingport Station. The IWBR core started operation in the Shippingport Station in the Fall of 1977 and is expected to be operated for about 4 to 5 years. At the end of this period, the core will be removed and the spent fuel shlpped to the Naval Reactors Expended Core Facility for a detalled ecamination to verify core performance including an evaluation of breeding characteristics.

In 1976, with fabrication of the Shipplngport IWBR core nearing completion, the Energy Research and Development Administration, now DOE, established the Advanced Water Breeder Applications (AWBA) program to develop and disseminate technical information which would assist U. S. Industry in evaluating the IWBR concept for commercial-scale applications. The program is exploring some of the problems that would be faced by industry in adapting technology confirmed in the IWBR program. Information being developed includes concepts for commercial-scale prebreeder cores which would produce uranium-233 for light water breeder cores while producing electric power, improvements for breeder cores based on the technology developed to fabrlcate and operate the ShIpplngport IWBR core, and other information and technology to ald in evaluating comercialscale application of the IWBR concept.

All three development programs (Pressurized Water Reactor, LIght Water Breeder Reactor, and Advanced Water Breeder Applications) are under the technical direction of the Division of Naval Reactors of DOE. They have the goal of developing practical improvements in the utilization of nuclear fuel resources for generation of electrical energy using water-cooled nuclear reactors.

Technical information developed under the Shippingport, IWBR, and AWBA programs has been and will continue to be published in technical memoranda, one of which is this present report.

Revised 1-17-80 


\section{TABLE OF CONTENTS}

\section{Introduction}

II. Kịematics

III. Field Equations

A. Mechanical Effects for Quas1-Static Processes

B. Thermal Effects

IV. Constitutive Assumptions

V. The Principle of Material Frame Indifference

VI. Consequences of the Principle of Materlal Frame Indifference and $\Gamma$-Invariance

VII. Restrictions Imposed by the Clausius-Duhem Inequality

VIII. Material Symetry

IX. The Inelastic Strain Rate

X. A Form of the Free-Energy Function

XI. Summary

References 


\section{ABSTRACT}

A Thermomochanical Theory of Materials Undergoing Large Elastic and Viscoplastic Deformation (AWBA Development Program)

S. E. Martin

J. B. Newman

A thermomechanical theory of large deformation elastic-inelastic material behavior is developed which is based on a multiplicative decomposition of the strain. Very general assumptions are made for the elastic and inelastic constitutive relations and effects such as thermally-activated creep, fast-neutron-flux-induced creep and growth, annealing, and strain recovery are compatible with the theory. Reduced forms of the constitutive equations are derived by use of the second law of thermodynamics in the form of the Clausius-Duhem Inequality. Observer Invariant equations are derived by use of an Invariance principle which is a generalization of the principle of matertal frame indifference. 
A Thermomechanical Theory of Materials Undergoing Large Elastic and Viscoplastic Deformation

(AWBA Development Program)

S. E. Martin

J. B. Newman

\section{Introduction}

Intuitively, the deformation of many materials can be regarded as a comblnation of two deformations, one part called "elastic" which 1s determined by the current temperature and load, and a part called "1nelestic" which displays a dependence on the history of the temperature and load. This Intultive concept can also be supported on a molecular basis. The elastic part of the deformation can be attributed to chinges in intermolecular spacing and the inelastic part attributed to dislocation motion, recrystallization, twinning, grain boundary sliding and other microscoplc phenomena.

In the amall strain theory of pisaticity [1], or the small strain theory of viscoplasticity [2], the strain at a point is decomposed into a sum of an

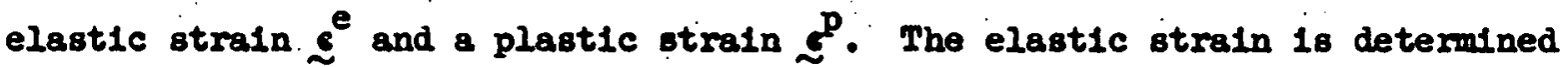
from the infinitesimal theory of elasticity while the plastic strain is determined from an Incremental flow law such as the von Kises flow law [1]. In some applications both the elastic and the 1nelastic otrains are large and of approximately the same order of magnitude. For example, Lee [3] polnts out that elastic volume reductions of $2 \%$ or mose are experienced in explosive wave propagation. In light water reactors, elastic thermal strains of $3 \%$ and inelastic strains of $5 \%$ are predicted to occur in ceramic fuels during normal operation. The use of the infinitesimal theory to analyze strains of this magnitude can result in unacceptable errors and inconsistencies.

* Throughout this paper, numbers in brackets denote 1tems in the list of References. Numbers in parenthesis denote the equations included in the text. 
In a theory of large deformation elastic-1nelastic behavior it 18 natural, as in the small strain case, to decompose the strain into an elastic and an inelastic component. However, because the decomposition of the strain is not unique, the implementation of this concept for finite deformations is more complex than for small deformations. Both additive [4] and multiplicative [3] decompositions are possible. The kinematics associated with such decompositions have been discussed by Lee [5], Sideroff [6], Kleiber [7] and Freund [8].

Theories of material behavior which utilize finite-strain decompositions have been formulated by Lee [5], Green and Naghdi [4], and Freund [8] to model elastic-plastic behavior, and by Kratochvil [9] to model elasticviscoplastic behavior. In the present paper, Kratochvil's theory is reformulated and extended by using an invariance requirement which combines the principle of material frame indifference and the $\Gamma$-invariance proposed by Sideroff [6]. A set of constitutive assumptions is used which allows a particularly straightforward application of the invariance requirement and, using the method developed by Coleman and Noll [10], the Clausius-Duhem inequality is used to further restrict the form of the constitutive assumptions. The resulting equations Imply a finite strain decomposition similar to the one assumed at the outset by Lee [5]. Although no specific assumptions are made about the Inelastic part of the strain, effects such as thermallyactivated creep, fast-neutron flux-induced creep, fast-neutron flux-induced stress-free growth, annealing, and strain recovery are compatible with this theory and can be included in the constitutive equations for the inelastic 
strain. The equations expressing materlal symmetry are developed and the concepts of elestic and inelastic material symmetry are shown to arise in a natural way. Finally, a simple form of the elastic constitutive equation Is derived which is sultable for irrotational deformations of materials subject to large inelastic and thermal expansion strains, but small stressinduced elastic strains. This form of the elastic constitutive equation and the multiplicative elastic-inelastic strain decomposition has recently been incorporated into the CYGRO computer program [16] for the analysis of nuclear reactor fuel rod behavior.

\section{KLnemat1es}

In continurum mechanics a body $B$ is a set of polnts $\left\{z_{2}, z_{2}, \cdots\right.$. $\}$ called materlal points. A one-to-one mapping $x$ from B into a three-dimensional vector space $\nabla^{3}$ 1s called a configuration of the body. If $\underline{x}_{1}(z)$ and $\underline{x}_{2}(x)$ are two configurations, and the position vectors of material points in conflguration 1 are denoted by $\underline{X}$ whlle position rectors in conflguration 2 are denoted by $\ddot{x}$, the mappling from configuration 1 in $v^{3}$ to configuration 2 In $v^{3}$ defined by

$$
\underline{x}=\underline{x_{2}}\left\{\underline{x}_{1}^{-1}(\underline{x})\right\}=\underline{\underline{\theta}}(\underline{x})
$$

is called a deforation of the body B Pron conflguration $\underline{x}_{1}$ to configuration $\underline{x}_{2}$. The derivative of the runction $\$$ at the location $X$ is the second-order tensor $\underset{\sim}{\mathrm{P}}$ called the deformation gradent. Intultively, $\underset{\sim}{\mathrm{F}} 18$ the lineer nunction which nost closely approximates the function $\theta$ in the nelghborhood of $\underline{x}$.

- Turougbout this paper quantities which aro vectors are indicated by plecing $a$ bar under the symbol for the quantity and tensor quantities are 1ndicsted by placing a t1lde under the symbol for the quantity. Functions whose values are vectore or tensors are aleo distingulabed in a corresponding nanner. 
As an illustration of these concepts, consider the behavior of a netal bar subjected to simple extension. This example is illustrated in Figure 1; Initially, the body is in the configuration $\underline{x}_{1}$ called the reference configuration. We assume that a system of forces deforms the body unfformly from the conf1gura-. tion $\underline{x}_{1}$ to the configuration $\underline{x}_{3}$ and that removal of the force systen causes the body to occupy the stress-free conflguration $\underline{x}_{2}$.

From Figure 1 it 18 evident that many relationships exist between the functions shown there. For example,

$$
\begin{aligned}
& \underline{A}_{t}=\underline{x}_{3}\left\{\underline{x}_{1}^{-1}(\underline{x})\right\}=\underline{x}_{3} \cdot \underline{x}_{1}^{-1}, \\
& \mathscr{A}_{1}=\underline{x}_{2} \cdot \underline{x}_{1}^{-1}, \\
& \stackrel{\Delta}{\Rightarrow}=\underline{x}_{3} \cdot \underline{x}_{2}^{-1} .
\end{aligned}
$$

The deformations defined above are related by

$$
\stackrel{\theta}{-t}=\stackrel{\theta}{-} \cdot \stackrel{\theta}{-}
$$

The deformations $\theta_{t}, \theta_{e}$ and $\mathscr{D}_{-1}$ w1ll be called the totel, the elastic, and the Inelastic deforwations, respectively. From the chain rule for multivariate derivatives, equation (2.1) gives

$$
E_{t}=F_{1}
$$




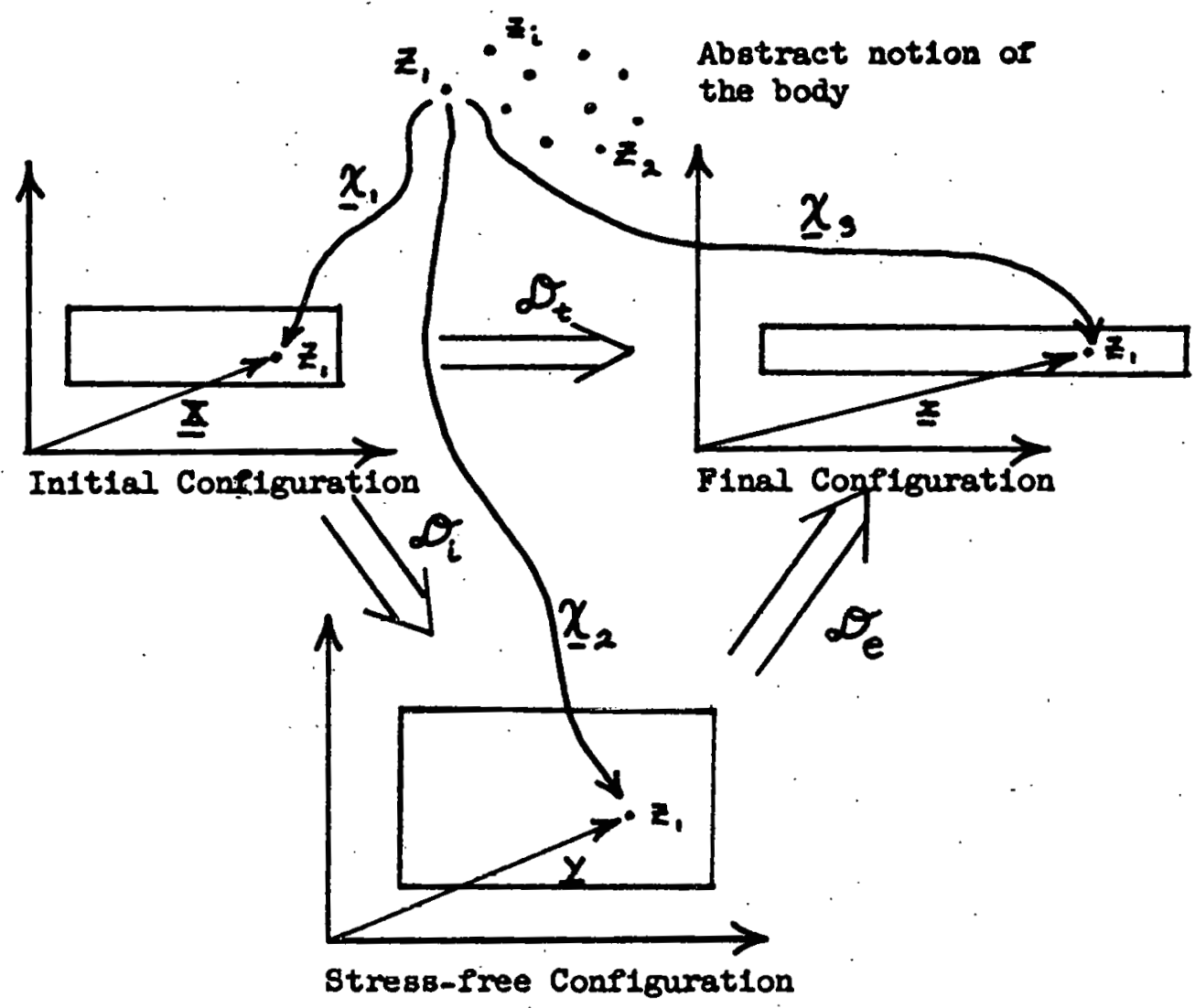

FIGURE 1

Simple Bxtension of a Metal Bar

where $\underset{\sim}{F_{t}} ; \underset{\sim}{F_{e}}$ and $\underset{\sim}{\mathrm{F}}$ are the deformation gradients corresponding to the total, the elastic, and the inelast1c deformations.

We remark that the above example was given in order to motivate the definitions which wlll be given presently. Our purpose 18 to formulate a local constitutive equation which relates varlables such as stress and strain which are defined at a point in the material. Accordingly, we take the local strain decomposition given by

$$
F_{t}=\stackrel{p}{F_{1}}
$$


as our sterting point! The resson for abandoning consideration of the global mappings $\underline{x}$ and the elobal deformations $\theta$ in faror of the local relation (2.3) is that a stress-free state will generally not exist for non-uniform deformations. If the stress-free state does not exist, $F_{0}$ and I will not correspond to independent deformations of a contimuous body. Although scine authorg $(6.8$. [7]) have chosen to regard the stress-free state as extating in a non-feuclidean space and have extensively developed the corresponding klnemațics, we do not belleve that this approach 18 necessary. The consideration of /global mappings should only notivate the form of the local constitutive equations.

III. Field Bquations

A. Nochanical Effects for Qussi-8tatic Processes

In the absence of couple-stresses the equations of equilibriun are expressed by Cauchy'/s laws, given by (see e.g. [11])

$$
\nabla \cdot \underline{\underline{T}}(\underline{x}, t)+\rho(\underline{x}, \underline{t}) \underline{b}(\underline{x}, t)=\underline{0}
$$

and

$$
\underset{\sim}{T}=\stackrel{T}{T}^{T}
$$

where $\nabla \cdot 18$ the divergence operator, I 18 the Cauchy (or true) stress tensor, $x$ is the spatial position vector, $t$ is time, $p$ is the mass per unit volume, and $\underline{b} / 18$ the body force per unit mass. Conservation of mass 18 expressed by 


$$
\frac{\partial p(\underline{x}, t)}{\partial t}+\nabla \cdot[p \underline{\underline{x}}(\underline{x}, t)]=0
$$

where $I$ is the particle velocity.

Bquations (3.1) - (3.3) can be used to dertve the wechanical onergy transfer theoren:

$$
\int_{\partial P_{t}}(\underline{I} z) \cdot \underline{n} d A+\int_{P_{t}} p \underline{b} \cdot \underline{I} d V=\int_{P_{t}} t r\{\underset{\sim}{I}\} d V
$$

where $P_{t} 18$ the region of space occupled by the body at $t$ ime $t, \partial P_{t} 18$ the boundary of $P_{t}, \underline{n} 18$ the outward normal to $\partial P_{t}, t x\{\}$ denotes the trace and $\underset{\sim}{\sim}$ is the spatial gradient of the velocity f1eld. The three integrels in (3.4) have a simple interpretation. The f1rst integral represents the rate of work done on the body by surface forces and the second integral represents the rate of work done on the body by body forces. If we were dealing with a rigid body, the work done by external forces would go into the kinetic energy of the body. However, kinetic energy is neglected in (3.4). and the third integral will be zero for rigid motions. Therefore, the third Integral in (3.4) represents the rate of work expended in deforming the body. Th18 Integral vill be denoted $\theta\left(P_{t}\right)$. The term tr $\left\{I_{I}\right\}$ will be denoted by and referred to as the stress power.

\section{B. Thermal EfPects}

The rate of Plow of energy 1nto the body due to therial effects id denoted $Q\left(P_{t}\right)$ and 18 given by 


$$
Q\left(\dot{P}_{t}\right)=\int_{\partial P_{t}} \underline{q}(\underline{x}, t) \cdot \underline{n} d A+\int_{P_{t}} r(\underline{x}, t) p(\underline{x}, t) d V
$$

where $q$ 1s the heat flow per unit area per unit time into the body and $r$ is the heat oupply per unit mass. We assume that there exists a quantity $(\underline{x}, \dot{t})$ called the ppecific internal energy such that

$$
\underline{U}\left(P_{t}\right)=\int_{P_{t}} e(\underline{x}, t) \rho(\underline{x}, t) d V
$$

where $B\left(P_{t}\right)$ is the internal energy of the body. The energy balance axiom, or principle of conservation of energy, 18 expressed by

$$
\frac{d}{d t}\left[B\left(P_{t}\right)\right]=Q\left(P_{t}\right)+Q,\left(P_{t}\right)
$$

The local form of (3.7) 1s given by

$$
\mu t=t r\{\underline{L}\{+\nabla \cdot q+p r
$$

where a superposed dot denotes material time differentiation defined by

$$
(\underline{x}, t)=\frac{\partial \varepsilon}{\partial t}+\underline{\underline{r}}(\underline{x}, t) \cdot \nabla \cdot(\underline{x}, t)
$$

The Clausius-Duhem diasipation inequaltty, expreagling the second law of thermodymantcB, takes the form 


$$
\begin{aligned}
& \text {-9- } \\
& \frac{d}{d t} B\left(P_{t}\right) \geq \int_{\partial P_{t}}\left(\frac{q}{\theta}\right) \cdot \underline{n} d A \int_{P_{t}}\left(\frac{r}{\theta}\right) \rho d v
\end{aligned}
$$

where $\theta 18$ the absolute temperature and

$$
\text { II }\left(P_{t}\right)=\int_{P_{t}} \eta(\underline{x}, t) \rho(\underline{x}, t) d V
$$

18 the entropy of the body and $\eta(\underline{x}, t)$ 1s the entropy per untt mass. The local form of equation (3.10) is given by

$$
\rho \dot{\eta}-\rho\left(\frac{r}{\theta}\right)-\nabla \cdot\left[\frac{q}{\bar{\theta}}\right] \geq 0 \text {. }
$$

In terms of the Helmboltz free-energy $\downarrow$, defined by

$$
t=e-\eta \theta
$$

equation (3.8) can be used to reduce the dissipation inequality to the form

$$
-\rho(\dot{\gamma}+\eta \dot{\theta})+\operatorname{tr}\{\underline{L}\}+\left(\frac{1}{\theta}\right) \underline{q} \cdot \nabla \theta \geq 0
$$

where, agala, a dot denotes material tine differentiation. IV. Const1tutive Assumpt1ons

In the flollowing pections ve shall use the results of the preceding section with the principle of material frame indifference and the symetries of the materlal to derive the general form of a constitutive equation describing 8lmultaneous elastic and inelastic deformations. The resulting equations 
will suggest the functional forms/required to represent s1gnificant processes of viscoplasticity including annealing and strain recovery upon loading or reduced loading.

The derivation will make use of the concept that thermoelastic deformat1ons occur without dissipation of energy, while viscoplastic deformations Inevitably involve dissipation. Bome of this dissipation results in ilocal beating, while the remsinder acts to cause distortions of the crystal structure that may prove to be partially recoverable under certain circunstances. Accordingly, we make the following const1tutive assumptions.

(A) The Helmbaltz free-energy 1 is given by

$$
\varphi \hat{\imath}\left(\underline{F}_{e}, \underline{F}_{1}, \theta, \sigma_{1}, \ldots, \sigma_{R}, \xi_{1}, \ldots, \xi_{M}\right)
$$

The G's are scalars representing externally controlled influences on the material behavior such as the effects of fast-neutron flux. The $\xi^{\prime} s$ are scalar internal variables, such as dislocation density, which characterlze the state of the material.

(B) The internal variables are determined from rate equations such as

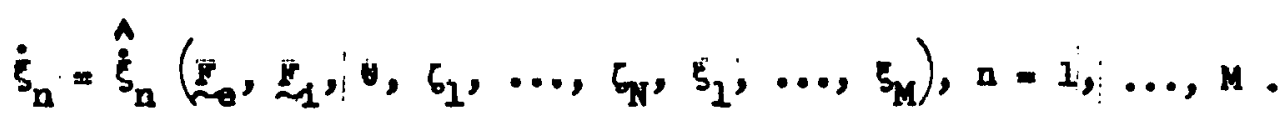

(c) We assume that the Cauchy stress tensor 18 determined by the two equations

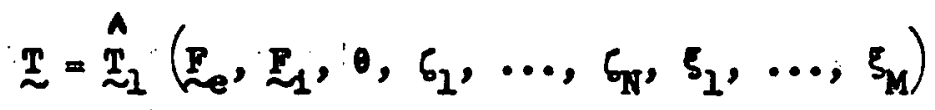


and

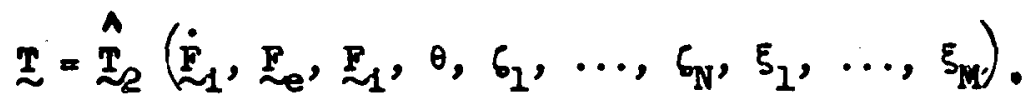

The assurption that there are two 1ndependent equations whlch determine the stress 18 a generalization of the 1des that the stress can be calculated elther from a knowledge of the elastic strain or from a knowledge of the inelastic otrain rate. Alternatively, one could solve (4.3) for $E_{\theta}$, solve $(4.4)$ for $\dot{F}_{1}$, and then refer to these as the elastic and inelastic stress relations respectively. As will be show below, writing the stress relations in the form of $(4.3)$ and $(4.4)$ alloris a particulariy stralghtforiard application of the principle of material frame indsfference.

(D) The entropy per unit mass $\eta 18$ given by

$$
\eta=\hat{\eta}\left(E_{e}, \mathbb{Z}_{1}, \theta, \sigma_{1}, \ldots, \varepsilon_{T}, \xi_{1}, \ldots, \xi_{X}\right)
$$

(B) The heat elux per unit area $q$ 1s given by

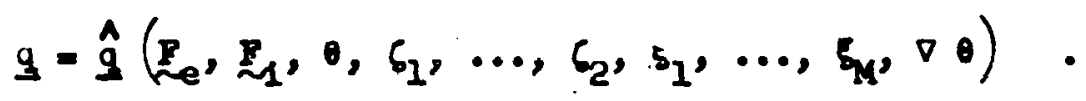

where $\nabla \theta$ is the spatial temperature gradient. 
V. The Principle of Material Frame Indifference

The principle of material frame indifference, which was first, explicitly stated by Noll [12], asserts that if two observers who are rotating (and possibly translating) relative to one anotber observe the deformation of a material and calculate its stress (or other quantities such as heat flux) from the constitutive equations, they should get the sane answer. Here, "sane" must be interpreted in a phjsical sense because the relative rotation of the observers must be accounted for when interpreting the results. Although this principle seems obvious, it is surprising how essily it can be vlolated when constitutive equations are postulated. For the present analy818 the Implications of this principle are that the runctions postulated In the constitutive assumptions (4.1) - (4.6) are not arb1trary, but must be subject to certaln restrictions. Our objective 18 to re-write equations (4.1) (4.6) In the most general form whtch vill autoratically satisfy Noll's principle of material trane indifference. Consequently, our equations wll always display the desired observer Independence.

If the orfentation of observer A relive to observer B is characterized by a time-dependent orthogonal (rotation) tensor $\mathrm{Q}_{1}$, it can be shown that
$(\mathbb{Z})_{A} \quad=\quad Q_{1}(\overline{\mathbb{Z}})_{B}$
$(\dot{\vec{P}})_{A}=\dot{Q}\left(\mathcal{L}_{B}\right.$
$(\underline{T})_{\Lambda}=Q_{1}(I) S_{B} \Omega_{1}^{T}$
$(t)_{A}=(t)_{B}$
$(\theta)_{A}=(\theta)_{B}$
$(\eta)_{A}=(\eta)_{B}$ 


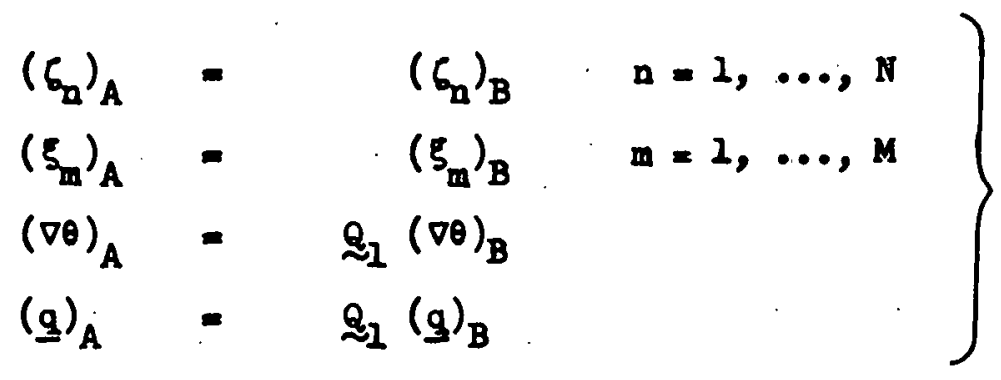

where $(\cdot)_{A}$ and $(\cdot)_{B}$ Indicate the quantity as observed by observer $A$ and observer B respectively. In other words, if observer A sees the quantities denoted by $(\cdot)_{A}$ then observer B should see the quantities $(\cdot)_{B}$ elven by (5.1) If be 18 seeling the aame physical event.

The next step in Irvest1gating the consequences of the principle of material frane Indfference is to substitute the equivalences (5.1) Into the constitutive equations (4.1) - (4.6) in order to determine the conditions that the equations must atisfy. Before dolng this however, we observe that

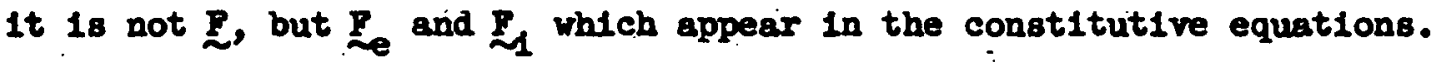

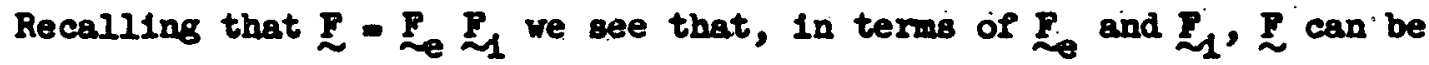
replaced by $Q_{i} \underset{Z}{ }$ in a variety of ways. For example; if $Q_{2} 18$ any orthogonal tensor, replacing $\underline{F}_{e}$ by $Q_{1} \underline{q}_{e} Q_{Q}^{T}$ and replacing $\underline{\mathcal{F}}_{1}$ by $Q_{2} F_{1}$ 1s easily seen to be equivalent to replacing $\underset{\sim}{\mathrm{F}}$ by $\mathrm{Q}_{1} \mathrm{~F}$. The arbitrariness in the choice of $\mathrm{Q}_{2}$ reflects the fact that the orientation of the local inelastic configuration 18 not uniquely determined when $\underset{\sim}{I}$ is replaced by $\mathcal{I}_{\mathcal{L}} \underset{\sim}{\mathrm{I}}$. In other words, the Inelastic strain consists of the orfginal strain ${\underset{\sim}{1}}_{1}$ followed by a rotation $Z_{e^{\circ}}$ Tmis $i_{Q}$ determines the orlentation of the local inelastic configuration. Next, the elastic part of the strain consists of undoing the rotation $Q_{2}$ by application of $Q_{2}^{T}$, stretching the material by $F_{e}$, and then applying a rotation $Q_{1}$. Clearly, the net reault of all of this 18 to replace the original $\underset{Z}{\sim}$ by $\underset{\mathcal{Z}}{\mathbb{P}}$. 
We will require that the constitutive equations be insensitive, or Invariant, to an intermediate rotation of the local inelastic configuration.

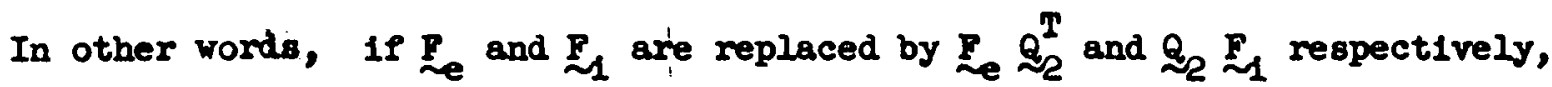
the quantities $\downarrow, \dot{\xi}, \underset{T}{\mathrm{~T}} \eta$ and $\underline{\mathrm{q}}$ predicted by the const1tutive equations $v 1 \mu$ be unchanged. This invarlance to an intermediate rotation was used by Green and Naghdi [4] and by Sideroff in [6] where 1 it 18 called $\Gamma$-invariance.

Nore generally, we observe that $\underset{\sim}{\mathcal{L}}$ can also be replaced by $\mathrm{Q}_{1} \underset{\sim}{\mathrm{P}}$ by

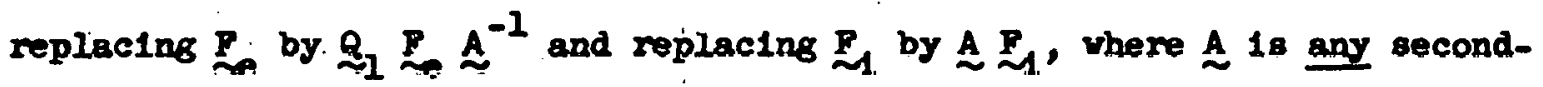
order tensor. For the principle of materlal frame ladifference to hold, $\mathrm{Q}_{1}$ must be arbltrary. However, this 18 not the case for the tensor $\mathrm{A}$. The two stress relations (4.3) and (4.4) must yield the same value of the stress. Bowever, when A 18 not an orthogonal tensor, in a certain sense the relative "amounts" of elastic and inelastic| straln are changed. For example, choosing A equal to $\mathrm{F}_{1}^{-1}$ would eliminate the inelastic strain and make the strain completely elastic. Certalnly under these conditions we would not, in general, expect the stress relations (4.3)|and (4.4) to y1eld the same stress. Therefore, we will only require that the equations be invarlant for the case in which A 18 orthogonal and argue that such invariance represents the linit of generality applicable to the present analysis.

VI. Consequences of the Principle of Materlal Frame Indifference and I-Invariance Comblning the two principles stated above, we obtain the followling:

Invartance Requirement

If the set of time-dependent quant1ties

$$
\left\{E_{0}, \mathbb{Z}_{1}, q, \eta, 0, \sigma_{1}, \ldots, \sigma_{1}, \xi_{1}, \ldots, \xi_{1,}, \nabla \theta, q\right\}
$$

satsify the constitutive equations $(4.1)-(4.6)$, then the quantities defined by 


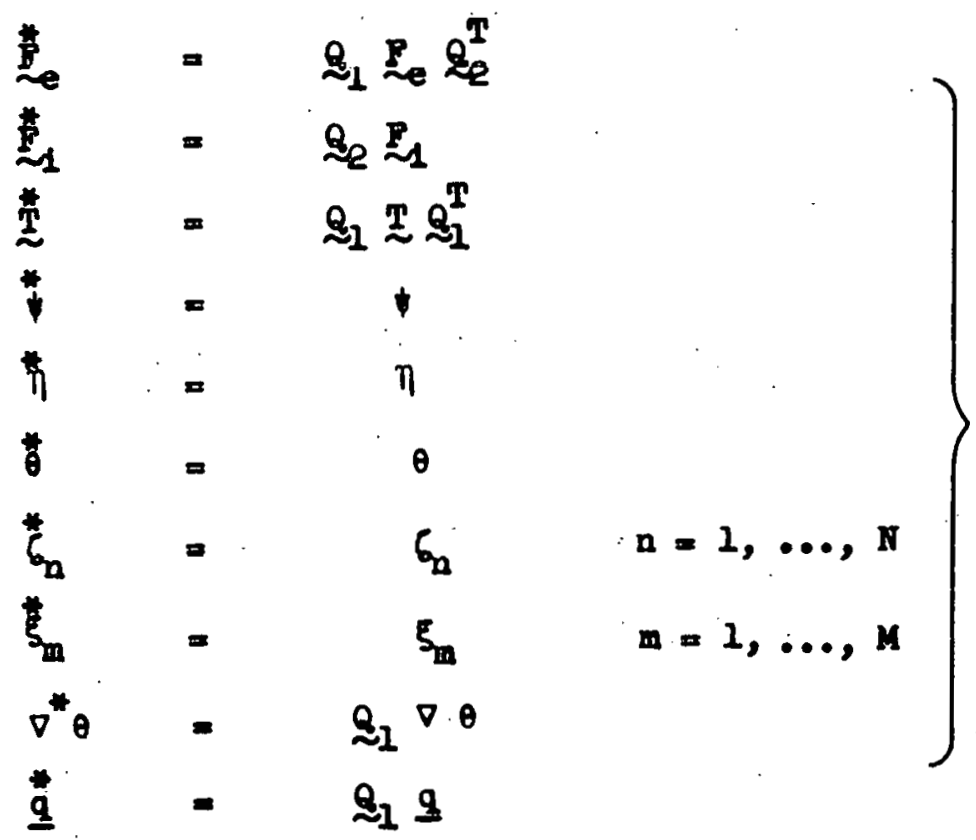

must also satisfy the constitutive equations for arbitirary cholces of the tiwe dependent. orthogonal tensors $\mathrm{g}_{1}$ and $\mathrm{g}_{2}$

For the first constitutive equation, equation (4.2), the Invarlance requirenent implies

$$
\begin{aligned}
& \hat{\imath}\left(F_{1}, \Sigma_{1}, 0, \zeta_{1}, \ldots, c_{N}, \xi_{2}, \ldots, \xi_{n}\right)
\end{aligned}
$$

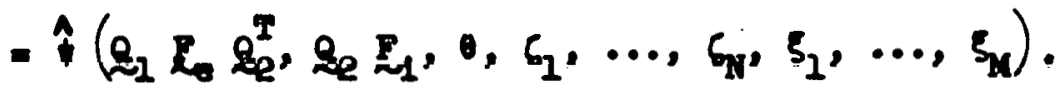

We now use the polar decomposition theorem to re-write ${\underset{z}{8}}_{8}$ and $\mathbf{F}_{1}$ Th1s theoren asserts that any tensor $\mathrm{I}$ can be written as a product of two unlque tensors $\underset{\sim}{\mathrm{R}}$ and $\mathrm{U}$, where $\underset{\sim}{\mathrm{R}} 1 \mathrm{~s}$ an orthogonal tencor and $\mathrm{U}$ Is a positive-derinite

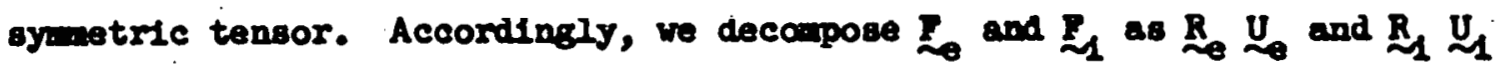
respectively. Using the decomposition for $\mathbb{f}_{1}$, the expression for calculating the Nree-energy looks like 


$$
\downarrow=\hat{\imath}\left(\underline{R}_{e}, \mathbb{R}_{1} U_{1}, \theta, \ldots\right)
$$

which can also be written

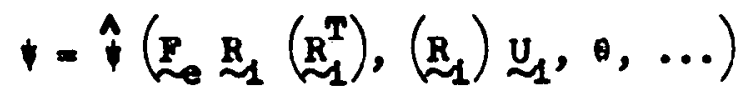

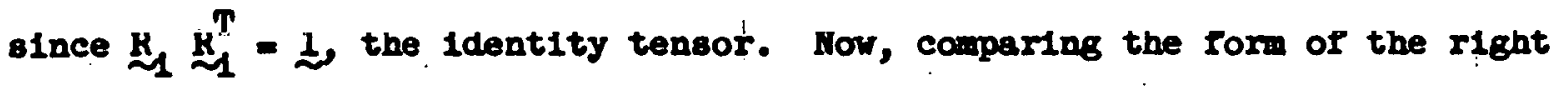
side of (6.3) with the right side of $(6.2)$, and letting $R_{1}$ assume the role of $Q$, we see that (6.2) Implies that we can write

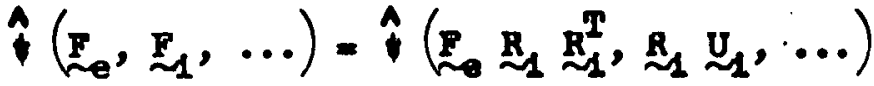

$$
\begin{aligned}
& =\hat{\dagger}\left(\mathbb{P}_{\mathbb{R}} \mathrm{R}_{1}, \mathrm{U}_{1}, \ldots\right) \text {. }
\end{aligned}
$$

In othor worde, tho invarlance requiromont exprosed by (6.2) 1mplios that if

$$
\varphi=\hat{\imath}\left(F_{e}, \underline{z}_{1}, \ldots\right)
$$

then must also be given by

$$
\downarrow=\hat{\imath}\left(\underline{F}_{\mathbb{R}}, \underline{\mathrm{R}}_{\mathcal{L}}, \ldots\right)
$$

The next step 18 to use the polar decomposition of $\underset{\mathrm{F}_{0}}{\mathrm{R}_{1}}$ In order to further reduce the equation. To obtain the polar decouposition of $\mathrm{P}_{e} \mathbf{R}_{1}$ we write it in the form

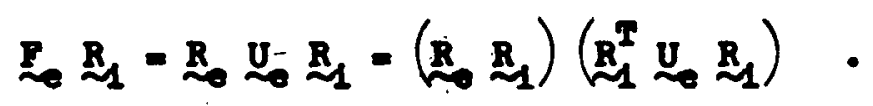




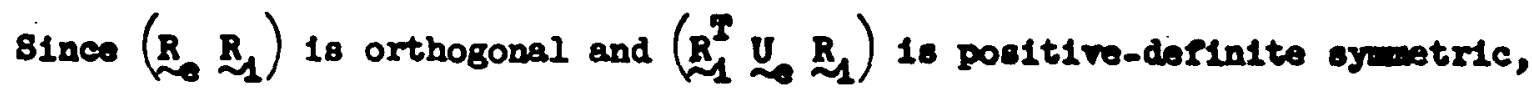
these terms represent the unique polar decomposition of $\underline{f}_{0} \mathbb{R}_{1}$.

Inserting this decorposition Into (6.5) ve obtaln

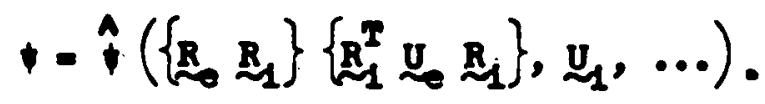

Uelng the Invarlance requirement (6.2), this tiwe with $Q_{2}$ equel to 1 and $Q_{1}$ equal to $\mathrm{R}_{0} \mathrm{R}_{1}$, we see that $(6.6)$ can be reduced to

$$
\begin{aligned}
& \downarrow=\hat{\imath}\left(\mathbb{R}_{1}^{T} \underline{J}_{e} \mathbb{R}_{1}, \underline{U}_{1}, \ldots\right) \\
& =\hat{\dagger}\left(\hat{U}, U_{1}, \ldots\right)
\end{aligned}
$$

where

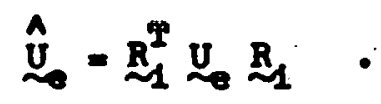

The main purpose of the priceding derlvation has been to show that if the free-energy 18 a nunction of the $\operatorname{set}\left\{f_{e}, \underset{\mathcal{F}}{\mathcal{P}}, 0, \sigma_{1}, \ldots, \xi_{1}, \ldots\right\}$, the Invarlance requirement lipplies that it is only necessary to bave a knorledge of the set $\left\{\hat{U}_{\theta}, U_{1}, \theta, G_{1}, \ldots, \xi_{1}, \ldots\right\}$. Th1s represents a s1genfficent reduction in complextty since $\hat{\mathrm{d}}_{\mathrm{e}}$ and $\mathrm{U}_{\mathcal{L}}$ are symetric, and thus represent

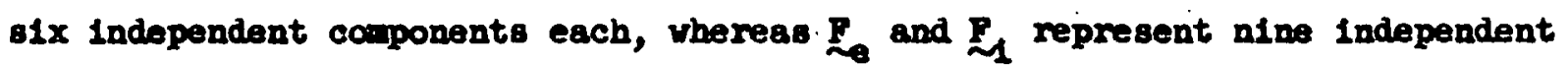
components each.

81nce the set of quent1ties $\left\{\hat{U}_{e}, U_{1}, \theta, \zeta_{1}, \ldots, \xi_{1}, \ldots\right\}$ 1s always oufficleat to determine the Pres-energy, we could have assumed at the outset that the free-energy was a function $f$ of this set. We w11l show that if this assumption 18 made the invariance requirenent places no restrictions on the form of $\hat{\dagger}$. 
Assume that the free-energy lis given by

$$
\downarrow=\tau\left(\hat{U}_{e}, \underline{N}_{1}, \theta, \sigma_{1}, \ldots, s_{1}, \ldots\right)
$$

where I Is an arbitrary function of Its arganents. Bince the class of arbitrary functions contains the claes of functione eatiafying the Invariance requirement, equation (6.9) does not represent any loss of generality; Next we apply the invarlance requirement to (6.9). Frad (6.1) we bave

$$
\begin{aligned}
& P_{t}^{*}=g_{1} I_{t} Q_{e}^{T} \\
& \stackrel{\mathrm{F}}{1}_{1}=Q_{2} \mathrm{P}_{1} \text {. }
\end{aligned}
$$

To investigate the invariance requirenents of (6.9) wo need to celculate $\mathbb{Z}_{-0}$ and $U_{-1}^{*}$ To do th1s, we write equations $(6.10)$ and $(6.11)$ in the forms

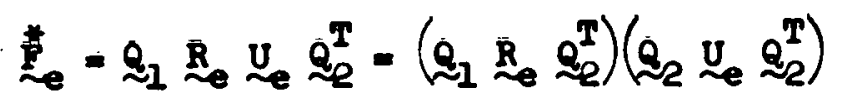

and

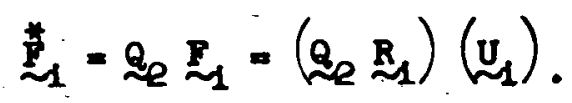

Thus, using the fact that the polar decomposition 18 unique, we see that

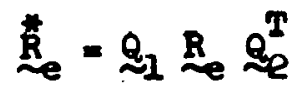

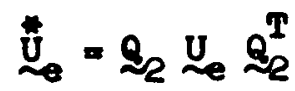

$$
\begin{aligned}
& \stackrel{\mathrm{R}}{\mathcal{L}}_{1}=Q_{2} \mathrm{R}_{1} \\
& \vec{U}_{1}=\underline{u}_{1}
\end{aligned}
$$




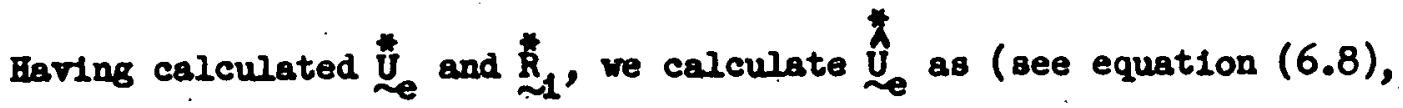

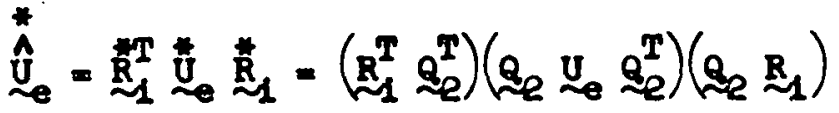

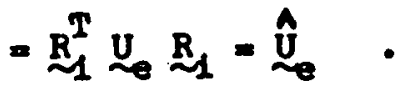

Therefore, $U_{\mathcal{I}}$ and $\hat{\mathrm{U}}_{e}$ are invarlant. This means that the free-energy equation (6.9) will autamatically sat18fy the invariance principle for an arbitrary function t.

In sumbary, we have shown that 19 the free-energy 18 expressed as a function of the $\operatorname{set}\left[E_{0}, \mathbb{F}_{1}, \theta, G_{1}, \ldots, \xi_{1}, \ldots\right\}$, the function must be of a special type and only a knowledge of the set $\left\{\hat{U}_{e}, \underline{\sim}_{1}, \theta, \zeta_{1}, \ldots, \zeta_{1}, \ldots\right\}$ 18 required- to determine the eree-energy. Alternatively, if we assume at the outset that the free-energy 18 a function of the set $\left\{\hat{u}_{e}, \underline{U}_{1}, \theta, \zeta_{1}, \ldots\right.$, $\left.\xi_{1}, \ldots\right\}$ then no restrictions are imposed upon the function by the Invariance requirement.

Golng through a sinflar analysis for the renainder of the constitutive equations, we obtain the following set of reduced equations.

$$
\begin{aligned}
& \downarrow=\tau\left(\hat{U}_{e}, U_{1}, \theta, \sigma_{1}, \ldots, \zeta_{N}, \xi_{1}, \ldots, \xi_{N}\right) \\
& \dot{\xi}_{n}^{-}=\tilde{\xi}_{n}\left(\hat{u}_{\theta}, \underline{u}_{1} ; \theta, \delta_{1}, \ldots, c_{n}, \xi_{1}, \ldots, \xi_{n}\right) \quad n=1, \ldots, n
\end{aligned}
$$

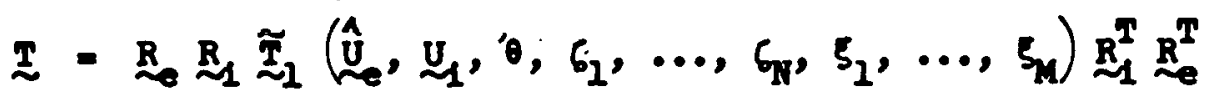

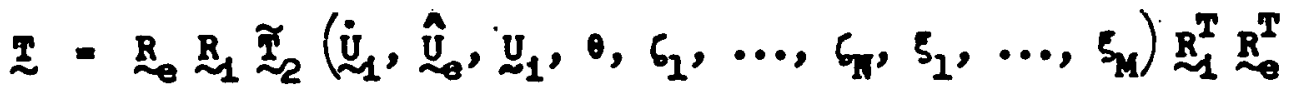

$$
\begin{aligned}
& \eta=\pi\left(\hat{U}_{0}, U_{1}, \theta, \sigma_{1}, \ldots, \sigma_{N}, \xi_{1}, \ldots, \xi_{N}\right)
\end{aligned}
$$

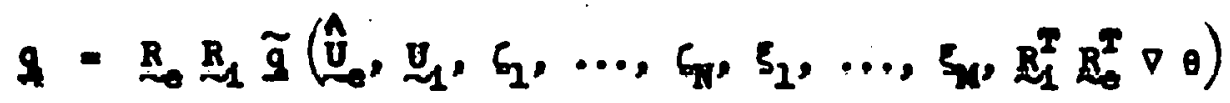


Although it may at the time have seemed like just a nicety to include $\underset{\sim}{\mathbb{F}}$ and $\underset{\mathcal{L}}{F_{1}}$ In the constitutive equation for the heat flux (4.6), the reduced form of the heat conduction equation, equation (6.24), shows that the material rotations are very important in determining the material response. In hindsight, it 18 easy to see that ${\underset{f}{e}}_{e}$ and $\underset{\sim}{F_{1}}$ must enter the constitutive equation for the heat flux if we are to consider materials which are aniootropic with regard to heat flow. For example, if the material is thermally anisotropic, a finite rotation of the material will affect 1 ts response to a temperature gradient. Equation (6.24) does not tell us exactly how the material response Is alterad, but Instead, tells us how the material rotations must enter the equation if all observers are to see the same response.

It 18 interesting to note that the original straln decouposition given by

$$
\underline{z}=\mathbb{F}_{-0} \mathbb{F}_{1}
$$

can be written

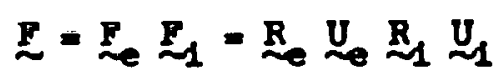

$$
\begin{aligned}
& =\left(\begin{array}{ll}
\mathbf{R} & \mathbf{R}_{1}
\end{array}\right)\left(\begin{array}{lll}
\mathbf{R}_{1}^{\mathbf{T}} & \mathbf{U}_{0} & \mathbf{Z}_{1}
\end{array}\right)\left(\mathbf{U}_{1}\right) \\
& =\left(R_{e} \mathbb{R}_{1}\right) \hat{U}_{e} \mathbb{U}_{1} \\
& =\underset{\mathbf{R}}{\hat{U}_{e}} \mathfrak{U}_{1}
\end{aligned}
$$

where $\mathrm{R}=\mathrm{N}_{\mathrm{e}} \mathrm{N}_{1}$. Thus, the use of $\hat{\mathrm{J}}_{\mathrm{e}}$ and $\mathrm{U}_{1}$ in the constitutive equations Is equivalent to using a strain docomposition of the form (6.25). I The strain decomposition (6.25) corresponds to a nornalization of the rotation occuring 
between the inelastic and elast1c stralns. The strain 18 decouposed Into a pure inelestic strotch, followed by a pure elastlc stretch, followed by a rotation. In developing his theory of plastielty, Lee [5] assumed at the outset a strain decomposition sinflar to $(6.24)$. We have shown that if the more fundamental strain decouposition

$$
\stackrel{P}{\sim}=\underset{\sim}{P}
$$

Is assumed, then the stretches $\hat{\mathrm{U}}_{e}$ and $\mathrm{J}_{1}$ in the decomposition

$$
\mathbb{Z}=\stackrel{R}{\sim} \underset{\sim}{\mathbb{U}} \underset{\sim}{\mathbb{U}}
$$

ar1se naturally as a consequence of the lavarlance requirement.

vII. Restrictions Imposed by the Clausius-Dubem Inequality

Equations $(6.19)$ - (6.24) are now substituted into the Clausius- Finem Inequality (3.13). In order to do this we mast flrst calculate is and to facllitate this we regard all quantities as functions of their position in a fixed reference conflguration. Differentiating (4.26) gives.

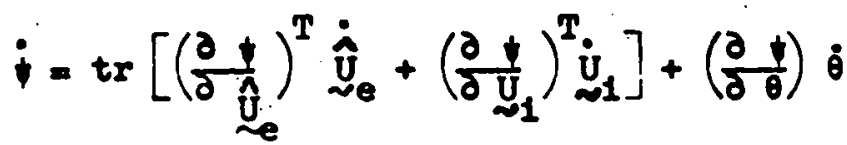

$$
\begin{aligned}
& +\sum_{n}\left(\frac{\partial}{\partial \xi_{n}}\right) \dot{\xi}_{n}+\sum_{n}\left(\frac{\partial}{\partial \xi_{n}}\right) \dot{\zeta}_{n}
\end{aligned}
$$

Substituting (7.1) 1nto (3.13) and re-arranging terms gives 


$$
\begin{aligned}
& \operatorname{tr}\left\{\left[I^{*}-p \hat{U}_{e}\left(\frac{\partial t}{\partial \partial_{e}}\right)^{T}\right] I\right\}-p\left[\frac{\partial t}{\partial \theta}+\eta\right] \dot{\theta}
\end{aligned}
$$

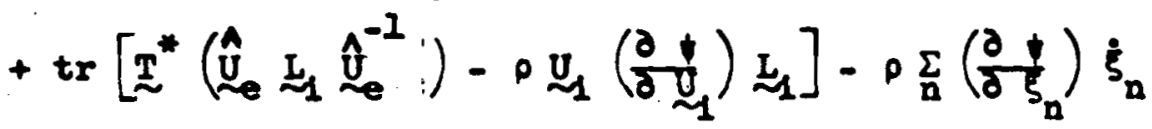

$$
\begin{aligned}
& -\rho \sum_{n}\left(\frac{\partial t}{\partial b_{n}}\right) \dot{\zeta}_{n}+\left(\frac{1}{\bar{\theta}}\right) g \cdot \nabla \theta \geq 0
\end{aligned}
$$

where

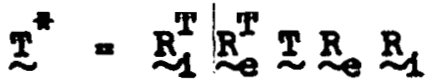

$$
\begin{aligned}
& L_{e}=\stackrel{\dot{A}}{U}_{e} \hat{U}_{e}^{-1} \\
& \underline{L}_{1}=\dot{\mathrm{U}}_{1} \mathrm{U}_{1}^{-1} \text {. }
\end{aligned}
$$

The tensors $I_{e}$ and $I_{1}$ will be called the elastic and inelastic velocity gradients respectively.

We now use the fact that it is possible, in principle, to vary $I_{8}$ and arbitrarly whlle holding all the remaining quantities in (7.2) P1xed. It is easy to show that this implies:

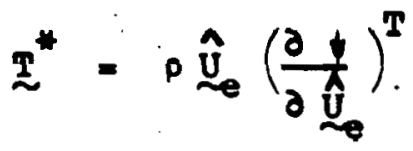

and

$$
\|=-\left(\frac{\lambda}{\partial t}\right) .
$$

These equations are of the same forms as the stress and entropy relations

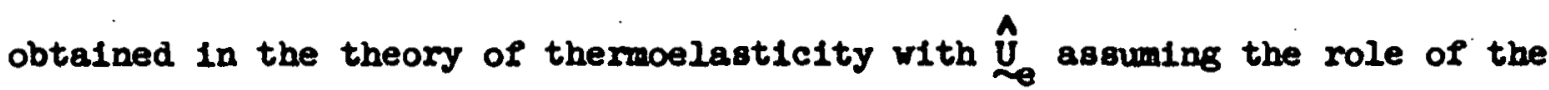
total stretch. These relations to a certain extent justify calling $\underset{\sim}{\mathrm{F}}$ the elast1c component of the deformation gradient. We remark that $(7.6)$ does 
not, In general, give a symetric stress tensor. However, 1f, as in the theory of nonlinear thermoelasticity, we make the assumption that is a function of $\hat{f}^{2}$, then the stress will always be symetric.

Since it is physically reasonable to assume that $\underline{q}$ is bounded as $\nabla \theta$ goes to zero, we can set $\nabla \theta$ to zero in (7.2) to obtaln

$$
\dot{w}_{1}-p \operatorname{tr}\{\underbrace{}_{1}\left(\frac{\partial t}{\partial d_{1}}\right) L_{1}\}-\rho \sum_{n}\left(\frac{\partial t}{\partial \xi_{n}}\right) \dot{s}_{n}-\rho \sum_{n}\left(\frac{\partial t}{\partial \zeta_{n}}\right) \dot{\zeta}_{n} \geq 0
$$

where $\dot{w}_{1}$ is defined by

$$
\dot{w}_{1}=\operatorname{tr}\left[T^{*} \cdot\left(\hat{U}_{e} I_{1} \stackrel{\hat{U}}{e}^{-1}\right)\right] \text {. }
$$

Recalling that the stress porer $\dot{w}$ is defined by

$$
\dot{v}=\operatorname{tr}\{\underline{I} \underset{\sim}{\sim}\}
$$

It is essy to show that the stress power can be written as a sum of two terms $\dot{w}_{1}$ and $\dot{w}_{e}$, where $\dot{v}_{1} 18$ defined by $(7.9)$ and $\dot{w}_{e} 18$ defined by

$$
\dot{w}_{e}=\operatorname{tr}\left\{q_{\sim}^{*} \underset{\sim}{L}\right\}
$$

81nce $v_{8} 18$ that portion of the stress power associsted with the elastic strain, and $\dot{w}_{1}$ 18 that portion assoclated with Inelastic strain; it 18 natural to refer to $\dot{v}_{e}$ and $\dot{v}_{1}$ as the elastic and Inelastic stress porers respectively. 
From the Inequality $(7.8)$ it is clear that strain recovery upon a reduction in stress, which Implies a negative Inelastic stress power, is possible only because of the dependence of $p$ on either $U_{1}, \xi_{n}$ or $\zeta_{n}$. That $18,1 f$ did not depend upon $U_{1}, \xi_{n}$ and $\xi_{n}$, the Inequality (7.8) would require that the inelastic stress power be greater than or equal to zero at all times. For example, for a bar belng inelastically stretched by a uniaxial force, the inequality $(7.8)$ would be vlolated if the bar inelastically shortened when the magnitude of the force was reduced. This type of inelastic shortening, or strain recovery, has been observed in real materials [13]. From $(7.8)$ we see that allowing to depend on the 6 's admits the possibllity of strain recovery only when the $\zeta^{\prime}$ 's are non-zero, 1.e. when the external varlables are changing. From the inequality $(7.8)$ it can be shown that. allowing the free-energy to depend upon the Inelastic strain $U_{1}$ does not properly model all aspects of strain recovery. By considering a one-dimensional case it can be shown that if $\frac{\partial U}{\partial U_{1}}$ is zero at some values of $U_{1}$, then strain recovery will not be allowed for certaln ranges of values of $U_{1}$. On the other hand, if we assume that $\frac{\partial t}{\partial U_{1}} \neq 0$ for all ralues of $U_{1}$, the stress rould always have to be greater than same positive value before the material could have a positive straln rate. The f1rst of these possibilities 18 not general enough and the second possibllity is not desirable. Therefore, in onder to properly model the material behavior assoclated with strain reconery we assume that the free-energy also depends upon the set of internal variables $S_{n}$. We belleve that many of the espects of strain recovery can be modelled by an approprlate cholce of the rate equations (7.8) which, in turn, determine the values of the Internal variables. 


\section{Mater1al 8youetry}

A rotation $Q$ of a body is an element of the symotry group of the body if the rotation does not affect the response of the material to subsequent deformations. As an example of this, consider a cube of material whose faces are aligned with a set of rectangular cartesian coordinate planes. If thls

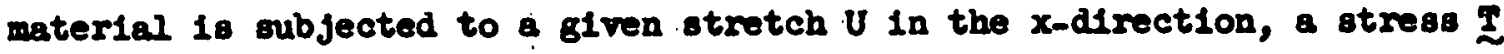
will be produced. Now suppose that instead of belag aluply. stretched, the cube had been first totated by $90^{\circ}$ about the z-axis and then stretched in the $x$-direction by an amount $U$. If the stress that results 18 the 8 ame as the stress I resulting when the material 18 stretched without prior rotation, then the material is behaving the sane in two different orientations. The set of all orlentat1ons which have the same response 18 known as the symetry Broup of the naterial.

Kathematically, this concept is expressed by the requirement that the material response be unchanged when the deformation gradient $\mathrm{P}$ is replaced by $\underset{\sim}{ } \mathrm{g}$, where $\mathrm{Q}$ is an orthogonal tensor. In other words the straining, represented by $\underset{\sim}{\mathrm{Z}} 1 \mathrm{~s}$ proceded; by the rotation $\mathrm{g}$. It 18 important to recogrize the logical dfference between material symetry, where the rotation precedes the deformation, and the principle of material frame indifference, where the rotation $Q$ folluw the deformation.

When the cecouposition

$$
\underset{z}{\mathbf{P}} \underset{\mathbf{P}}{\mathbb{Z}}
$$


1s used, we can write

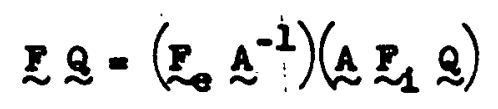

where $Q 18$ orthogonsl and $\underset{\sim}{\sim} 18$ any second-order tensor. Thus, replacing

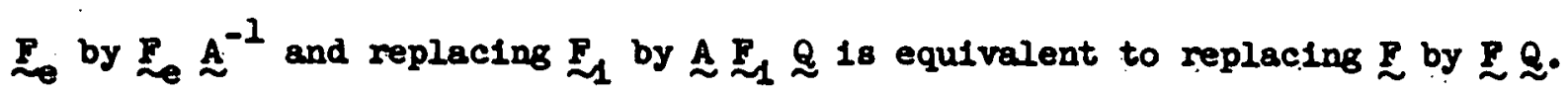
As in the section on material indifference, we will restrict the tensor $A$ to the class of orthogonal tensors. With this gssumption, it is easy tn shor that if

$$
\underset{\mathbf{E}}{\mathrm{E} Q}
$$

then

$$
\begin{aligned}
& U_{1} \rightarrow Q^{T} U_{1} Q \\
& \hat{U}_{e} \rightarrow Q^{T} \hat{U}_{e} Q \\
& \stackrel{\mathbf{R}}{\sim} \underset{\mathbf{R}}{\sim} \\
& \dot{\mathrm{U}}_{1} \rightarrow \mathrm{Q}^{\mathrm{T}} \dot{\mathrm{U}}_{1} \mathrm{Q}
\end{aligned}
$$

Making the substitutions $(8.3)-(8.6)$ into the reduced consitutive equations $(6.19) \div(6.24)$ g1ves

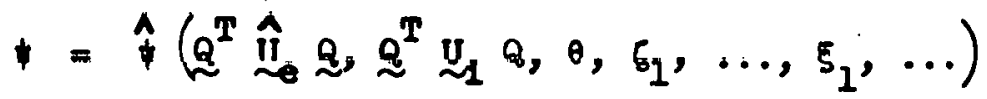

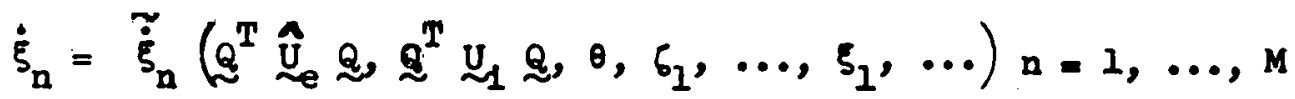

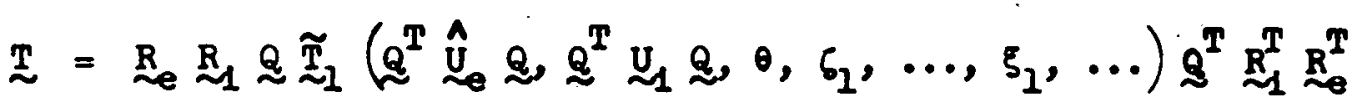

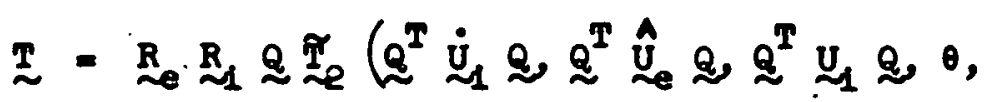

$$
\begin{aligned}
& \left.\sigma_{1}, \ldots, \xi_{1}, \ldots\right) Q^{T} \stackrel{R}{T}_{R_{e}^{T}}^{R^{T}}
\end{aligned}
$$




$$
\begin{aligned}
& \eta=\tilde{\eta}\left(Q^{T} \hat{\theta}_{Q} Q, Q^{T}{\underset{\sim}{L}}_{1} Q, \theta, \sigma_{1}, \ldots, \xi_{1}, \ldots\right)
\end{aligned}
$$

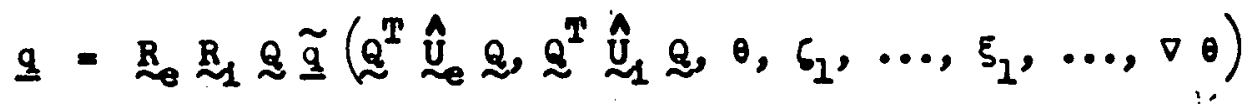

In general, the values of the time-dependent quantities $t, \dot{\xi}, \mathfrak{d}$, $\eta$ and $g$ calculated from (8.7) - (8.12) wll depend upon the cholce of the orthogonal tensor $\mathrm{Q}$. The set of all orthogonal tensors whlch leare the predicted values of a given equation unchanged from the value predicted when $Q=\frac{1}{\sim} 18$ called the symetry group of that equation.

In the theory presented here, the stress 18 determined by two Independent equations which define the elasticland lnelastic response of the material. In general, we would expect the sympetries of these two equations to be different. For example, a material could concelvably be shown to be elastically Lsotropic during short-tiwe tensile tests and shown to be Inelastically anisotrople during long-time creep tests. Since the stress is determined from the free-enersy by the stress relation $(7.6)$, it seems reasonable to expect the 1sotropy group for the elast1c stress equation (6.21) to be related to the 18otropy group of the froe-energy. For hyperelastic materials (1.e. elastic materials which have a atrain-energy function), Truesdell [14] has show that the orthogonal nembers of the 180tropy groups of the stress and free-energy are the same. A modifled form of Truesdell's proof will be used to show that the ssotropy group for the elast1c stress relation (6.21) conteins the 18otropy group for the free-energy.

Buppose that $Q 18$ an element of the 18otropy group of the stres8. . Substituting the stress relation (7.6) into (8.9) and simplifylang ylelds 
$-28-$

WAPD-TM-1472

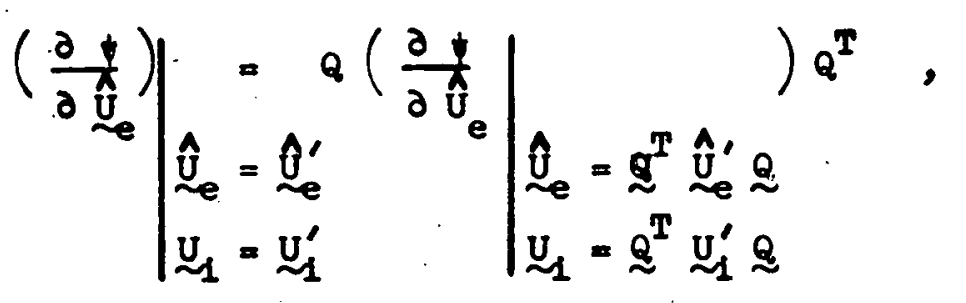

for the symmetry condition. This can be written as

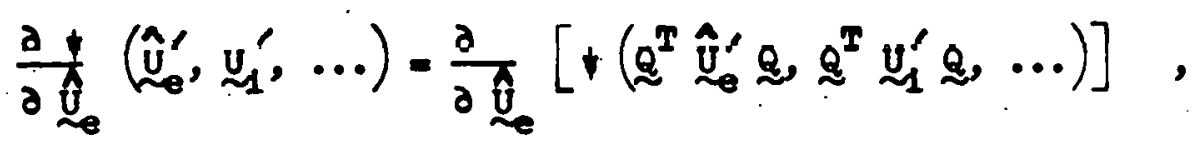

or

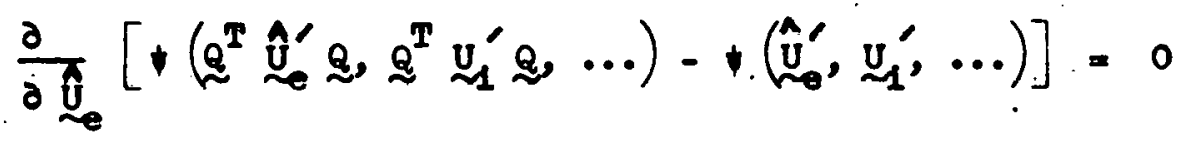

which implies that the quantity in brackets does not depend on $\hat{\mathrm{U}}_{-}$. Therefore,

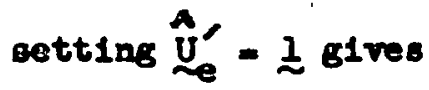

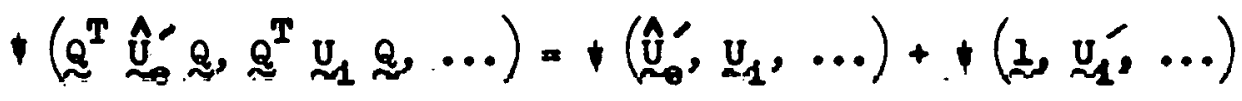

$$
\begin{aligned}
& \text { - }\left(\frac{1}{2}, Q^{T} \mathrm{u}_{1}^{\prime} Q, \ldots\right)
\end{aligned}
$$

since all the steps leading to $(8.14)$ are reversible, an orthogonal tensor Q 18 an element of the Isotropy group of the stress if and only $1 f(8.14)$

is satisfied.

Now, suppose $Q 18$ an element of the isotropy group of. to Then, by the definition of the isotropy group of $\downarrow$,

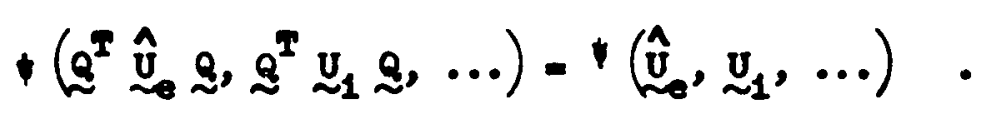


and 1 t 18 seen that (8.14) w1ll be satisfied. Thus $Q$ will be an element of the lsotropy group of the elastic stress equation (6.21). In the case where elther does not depend on $\mathbb{U}_{\mathcal{L}}$ or depends only upon the Invariants or $U_{1}$, equation $(8.14)$ reduces to

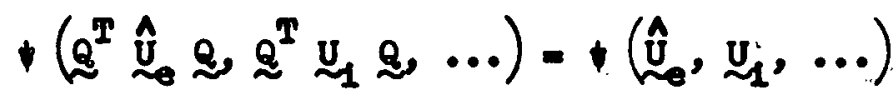

which shows that $Q 18$ an element of the 180tropy group of the free-energy. Therefore, in this case the lsotropy groups colnclde. In general, hovever, It seems that all we can say is that the 1sotropy group for the elastic stress relation contains the isotropy group for the free-energy. IX. The Inelast1c Strain Rate

From equations (6.21) and (6.22), we can write the elast1c and inelastic stress relations in the forms

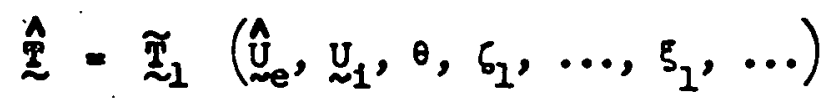

and

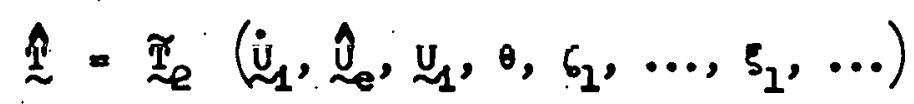

where

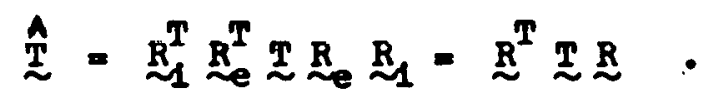

Although (9.2) 18 a good form of the inelast1c stress relation for theoretical calculations, in practice it is usually the inelast1c strain rate which is known as a function of stress. Therefore, we assume that (9.2) can be solved Por $\stackrel{1}{1}$ to obtaln 


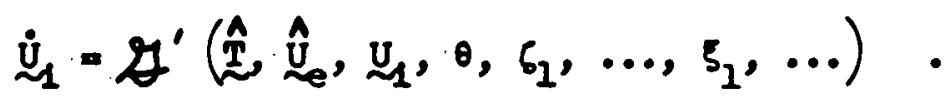

Next, if the elastic stress relation $(9.1)$ can be solved for $\hat{\mathrm{U}}_{\theta}$, then $\hat{\theta}_{0}$ can be eliminated from (9.4) to obtaln

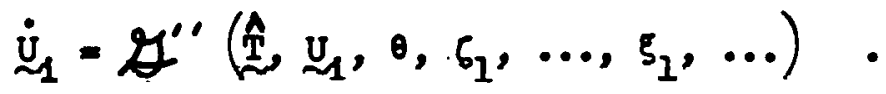

Post-multiplying by $\mathbb{U}^{-1}$ gives

$$
\Xi_{1}=\mathcal{H}\left(\stackrel{\hat{I}}{\underline{\underline{I}}}, \underline{u}_{1}, \theta, \zeta_{1}, \ldots, \xi_{1}, \ldots\right)
$$

where $I_{1} 18$ the inelastic volocity gradient. In one dimension and in the absence of elastic strain, the inelastic velocity gradient $L_{1}$ represents the rate of change of length per unit current length of the material and 18 the measure of strain rate usually used by metallurg1sts. Using equations (8.3)(8.6) and (8.10), it 18 easy to show that the inelastic symetry conditton becomes

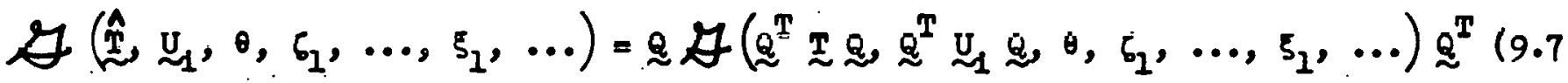

For 1sotropic Inelastic response, equation (9.7) implies that $\mathcal{A}$ must be an 1sotrople function of $\underset{\mathrm{I}}{\mathrm{I}}$ and $\mathrm{U}_{1}$. 


\section{A. Form of the Free-Energy Function}

We now specialize the foregolng theory and derlve a form of the freeenergy function which is sultable for Irrotational deformations of materlals subject to large thermal expansion strains. For this case, it is assumed that the free-energy depends only upon the elastic strain $U_{e}$ and the temperature $\theta$ and that the material has orthotropic symetry. "Thls implies that $\downarrow$ is of the form (see e.g. [15])

$$
\downarrow=\hat{t}\left(e_{1}, e_{2}, e_{3}, \theta\right)
$$

where the $e^{\prime} s$ are the principal engineering thermoelastic strains defined by

$$
e_{\ell}=\hat{U}_{e_{\mu}}-1
$$

If the temperature is fixed, the free-energy function will be of the form

$$
t=\tau_{\theta}\left(e_{1}, e_{i 2}, e_{3}\right)=\tau_{\theta}(e)
$$

where we can regard the $e_{k}$ as components of a vector $e$ in principal strain 8pace. In general, the form of the function $f$ will depend upon the temperature. Figure 2 shows what t might look like if there were only one strain component.

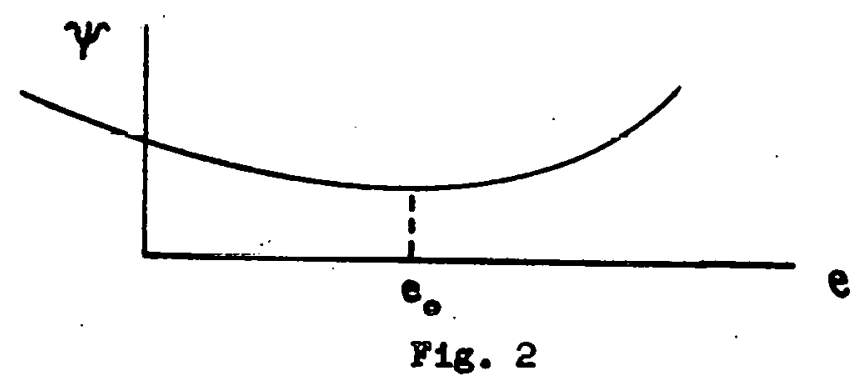

* A material has orthotrople symetry if 1 has $180^{\circ}$ symetry about three mutually orthogonal axes. 
In general, w11l have a minimum at some strain $e_{0}$. From the stress relation

$$
\stackrel{T}{T}^{*}=\rho \underline{U}_{e}\left(\frac{\partial \psi}{\partial \tilde{U}_{e}}\right)
$$

It is seen that $e_{0}$ is the stroin corresponding to zero stress, 1.e. It is thermal expansion strain. Intultively, changing the temperature causes the polnt $e_{0}$ to move. This effect can be modelled by a lateral transiation of the curve $t_{0}$ wth the amount of translation depending on $\theta$. To aecompliah thls we first assume that the temperature 18 held at the reference temperature $\theta_{0}$ and express as a complete second-derree polynominal in the at.rains.

$$
\begin{aligned}
t & =a_{0}+a_{1} e_{1}+a_{2} e_{2}+a_{3} e_{3}+a_{4} e_{1}^{2}+a_{5} e_{2}^{2} \\
& +a_{6} e_{3}^{2}+a_{7} e_{1} e_{2}+a_{8} e_{1} e_{3}+a_{9} e_{2} e_{3}
\end{aligned}
$$

The magnitude of 18 arbitrary to within an additive constant and we can therefore choose a equal to zero. Next, ve assume that 1 has a minimum at $e_{1}=e_{2}=e_{3}=0$. In other words, the stress will be zero whenever the body 18 at the reference temperature and the elastic strains are zero. Th1s implies $a_{1}=a_{2}=a_{3}=0$. Therefore

$$
\begin{aligned}
t(\underline{c}) & =m_{4} e_{1}^{2}+a_{5} e_{2}^{2}+a_{6} \sigma_{3}^{2}+a_{7} o_{1} e_{2}+a_{8} e_{1} e_{3} \\
& +a_{9} c_{2} e_{3} .
\end{aligned}
$$


$-33-$

WAPD-TM-1472

A translation of $\tilde{f}(\underline{e})$ is given by $\tilde{\dagger}(\underline{e}-\underline{\lambda})$ where $\underline{\lambda}$ is a vector whose components depend on the temperature. The minimum of the function $\tilde{(}(\underline{e}-\underline{\lambda})$ wi ll be at $\underline{E}=\underline{\lambda}$. Therefore, the components of $\lambda$ represent the stress free thermal strains.

Another way of seeing this 18 to substitute $e-\lambda$ for $\underline{e}$ in (10.6).

To do this we define $\underline{c}=\underline{e}-\underline{\lambda}$. Equation $(10.6)$ then becomes

$$
\begin{aligned}
\bar{f}(\underline{e}) & =\tilde{f}(\underline{\epsilon})=a_{4} c_{1}^{2}+a_{5} c_{2}^{2}+a_{6} c_{3}^{2} \\
& +a_{7} c_{1} c_{2}+a_{8} c_{1} c_{3}+a_{9} c_{2} c_{3}
\end{aligned}
$$

Because we expect the stress-Induced elastic deformation $\subseteq$ to be small, equation (10.7) should be a good approximation even for large strains. Finding the minimum for $\hat{\imath}(\underline{e}) 18$ accomplished by setting the partial derivatives of $\hat{i}(e)$ with respect to the $e_{1}$ equal to zero. From (10.7), this gives

$$
\left.\begin{array}{l}
\frac{\partial d_{1}}{\partial e_{1}}=2 a_{4}\left(e_{1}-\lambda_{1}\right)+a_{7}\left(e_{2}-\lambda_{2}\right)+a_{8}\left(e_{3}-\lambda_{3}\right)=0 \\
\frac{\partial t}{\partial e_{2}}=a_{7}\left(e_{1}-\lambda_{1}\right)+2 a_{5}\left(e_{2}-\lambda_{2}\right)+a_{9}\left(e_{3}-\lambda_{3}\right)=0 \\
\frac{\partial e_{3}}{\partial e_{3}}=a_{8}\left(e_{1}-\lambda_{1}\right)+a_{9}\left(e_{2}-\lambda_{2}\right)+2 a_{6}\left(e_{3}-\lambda_{3}\right)=0
\end{array}\right\}
$$


In matrix form these equations become

$\left[\begin{array}{lll}2 a_{4} & a_{7} & a_{8} \\ a_{7} & 2 a_{5} & a_{9} \\ a_{8} & a_{9} & 2 a_{6}\end{array}\right]=\left[\begin{array}{lll}e_{1} & \lambda_{1} \\ e_{2} & -\lambda_{2} \\ e_{3} & -\lambda_{3}\end{array}\right]=\left[\begin{array}{l}0 \\ 0 \\ 0\end{array}\right]$

or

$$
\underset{\sim}{\sim}[\underline{\underline{e}}-\underline{\lambda}]=\underline{0}
$$

Therefore, $e=\underline{\lambda} 18$ a solution of (10.10). If $\operatorname{det} \underline{A} \neq 0$ then $\underline{e}=\underline{\lambda}$ will be the only solution.

Next, suppose that in addition to translating, the $\tilde{f}(\underline{e})$ curve changes 1ts shape as the teaperature varles. We observe that allowing the components of the matrix A in (10.10) to depend upon the temperature $\theta$ does not affect the location of the minimum of $\tilde{f}(\underline{e})$. At any temperature, $\tilde{f}(\underline{e})$ w1ll st1ll have a minimum at $e=\lambda_{0}$ Therefore the $a_{1}$ in the free-energy function (10.7) can be regarded as arbitrary functions of $\theta$.

We observe that adding an arbitrary function of $\theta$ to the free-energy, function does not affect any of the preceding considerations. Fron (7.7) the entropy function 18 gtven by

$$
\eta=-\frac{\partial \eta}{\partial \theta}
$$


whlch shows that adding an arbitrary function of $\theta$ to the free-energy wili affect the entropy. Also, it is eas1ly shown that the speciflc heat at constant strain is given by

$$
k=-\theta \frac{\partial^{2} t}{\partial \theta^{2}}=\theta \frac{\partial \eta}{\partial \theta}
$$

Thus, the addition of an arbitrary function of $\theta$ to the free-energy can be used as a means of spectrying the specific heat of the material.

To simplify the calculations we will wite the free-energy function in the form

$$
+\sum_{\alpha=1}^{3} \sum_{\beta=1}^{3} b_{\alpha \beta} c_{\alpha} c_{\beta}+g(\theta)
$$

where $c_{\alpha}$ 18 defined by

$$
e_{\alpha}=e_{\alpha}-\lambda_{\alpha}(\theta), \quad \alpha=1,2,3,
$$

$g(\theta)$ is a suitably defined function of $\theta$, and $b_{\alpha \beta}$ is a matrix whose components are functions of $\theta$. From $(7.6)$, the stress will be given by

$$
T_{\alpha}=p\left(v_{e}\right)_{\alpha_{\beta=1}}^{3}\left(b_{\alpha \beta}+b_{B \alpha}\right) c_{\beta}
$$

where $\left(U_{e}\right)_{\alpha}$ denotes the oth component of $U_{e}$. Thls can be written

$$
T_{\alpha}=\rho\left(U_{e}\right)_{\alpha} \sum_{\beta=1}^{3} c_{\alpha \beta} c_{\beta}, \alpha=1,2,3,
$$


where $c_{\alpha \beta}$ is the symetric matrix defined by

$$
c_{\alpha \beta}=b_{\alpha \beta}+b_{\beta \alpha}, \alpha=1,2,3, \beta=1,2,3
$$

Using the definftion of $f$, equation (10.15) can be put into the form

$$
T_{\alpha}=\rho\left(U_{\beta}\right)_{\alpha} \sum_{\beta=1}^{3} e_{\alpha \dot{B}}\left[\left(U_{e}\right)_{\beta}-1-\lambda_{\beta}(\theta)\right] .
$$

Equation (10.17) is the elastic stress relation corresponding to the freeenexgy function (10.7).

Differentiating (10.13) with respect to $\theta$ and substituting into (10.10) Gives

$$
\eta=-\sum_{\alpha=1}^{3} \sum_{\beta=1}^{3}\left(b_{\alpha \beta}^{\prime} c_{\alpha} c_{\beta}-c_{\alpha \beta} \lambda_{\alpha}^{\prime} c_{\beta}\right)-B^{\prime}
$$

where $c_{\alpha \beta}$ is defined by $(10.16)$ and a prime denntep differentiation with respect to $\theta$. Substituting $(10.18)$ Into $(10.12)$ gives

$$
\begin{aligned}
c= & -\theta \cdot \sum_{\alpha=1}^{j} \int_{\beta=1}^{3}\left(b_{\alpha \beta}^{\prime \prime} c_{\alpha} c_{\beta}-2 c_{\alpha \beta}^{\prime} \lambda_{\alpha}^{\prime} c_{\beta}\right. \\
& \left.\left.-c_{\alpha \beta} \lambda_{\alpha}^{\prime \prime} s_{\beta}+c_{\alpha \beta} \lambda_{\alpha}^{\prime} \lambda_{\beta}^{\prime}\right)+8^{\prime \prime}\right\}
\end{aligned}
$$

From (10.19) it 18 seen that in the general case the specific heat will depend upon the strain. Equation (10.19) can be written in terms of the strains $c_{\alpha}$ as 


$$
\begin{aligned}
c= & -\underbrace{3}_{\alpha=1} \sum_{\beta=1}^{3}\left[b_{\alpha \beta}^{\prime \prime}\left(e_{\alpha}-\lambda_{\alpha}\right)\left(e_{\beta}-\lambda_{\beta}\right)-2 c_{\alpha \beta}^{\prime} \lambda_{\alpha}^{\prime}\left(\theta_{\beta}-\lambda_{\beta}\right)\right. \\
& \left.\left.-c_{\alpha \beta} \lambda_{\alpha}^{\prime \prime}\left(e_{\beta}-\lambda_{\beta}\right)+c_{\alpha \beta} \lambda_{\alpha}^{\prime} \lambda_{\beta}^{\prime}\right]+g^{\prime \prime}\right\}
\end{aligned}
$$

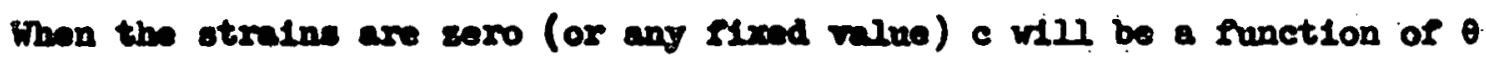
and the function $\mathrm{B}^{\text {Ad }}$ can be chosen to make $c$ any required function of temperature. Although the speciflc heat function at zero strain can be chosen arbitrarly, the dependence of $c$ on the itrain 18 determined by the stress strain response and the free-thermal-expansion runctions.

Returning now to the elastic stress relation (10.17), we will further 11nearize this equation. In terms of $\alpha$ defined by (10.14), equation (10.17) can be written

$$
\begin{aligned}
T_{\alpha} & =\left[\frac{p_{0}}{\left(U_{1}\right)_{1}\left(U_{1}\right)_{2}\left(U_{1}\right)_{3}}\right] \cdot\left[\frac{c_{\alpha}^{+1+\lambda_{\alpha}}}{\left(c_{1}+1+\lambda_{1}\right)\left(\beta_{2}+1+\lambda_{2}\right)\left(c_{3}+1+\lambda_{3}\right)}\right] \\
& \times \sum_{\beta=1}^{3} c_{\alpha \beta} c_{\beta}
\end{aligned}
$$

where the density has been expressed in terms of the density $p_{0}$ in the reference conf1guration and the stretches $\underline{U}_{1}$ and $\underline{U}_{e}$. Equation (10.21) can now be written in the form

$$
T_{\alpha}=\left(\frac{1}{V_{1}}\right) A_{\alpha} \sum_{\beta=1}^{3} z_{\alpha \beta} \dot{\varepsilon}_{\beta}
$$

where $v_{1}$ is the inelastic volume ratio defined by 


$$
v_{1}=\left(v_{1}\right)_{1}\left(v_{1}\right)_{2}\left(u_{1}\right)_{3},
$$

$A_{\alpha} 18$ given by

$$
A_{\alpha}=\frac{\varepsilon_{\alpha}+1+\lambda_{\alpha}}{\left(\varepsilon_{1}+1+\lambda_{1}\right)\left(\varepsilon_{2}+1+\lambda_{2}\right)\left(\epsilon_{3}+1+\lambda_{3}\right)}
$$

and the matrix $\hat{c}_{\alpha \beta}$ is given by

$$
\hat{c}_{\alpha \beta}=p_{0} c_{\alpha \beta}
$$

Because the 6's are small, we can expand the terms in the denominator of (10.24) in power series to obtain

$$
\begin{aligned}
A_{\alpha} & =\left[c_{\alpha}+1+\lambda_{\alpha}\right]\left\{\left[\frac{1}{\left(1+\lambda_{1}\right)}\right]\left[1-\left(\frac{1}{1+\lambda_{1}}\right)+\ldots\right]\right\} \quad \text { (10.26) } \\
& x\left\{\left[\frac{1}{\left(1+\lambda_{2}\right.}\right]\left[1 .\left(\frac{c_{1}}{1+\lambda_{2}}\right)+\ldots\right]\right\}\left\{\left[\frac{1}{\left(1+\lambda_{3}\right)}\right]\left[1-\left(\frac{c_{3}}{1+\lambda_{3}}\right)+\ldots\right]\right\}
\end{aligned}
$$

Substituting $(10.26)$ into $(10.22)$ and retaining only first-order terms In the e's yields

$$
T_{\alpha}=\left(\frac{1}{v_{1}}\right)\left(1+\lambda_{\alpha}\right) \sum_{\beta=1}^{3} \tilde{c}_{\alpha \beta} \epsilon_{\beta}
$$

where $\tilde{c}_{\alpha \beta}$ is a new matrix of temperature dependent elastic moduli defined by

$$
\tilde{c}_{\alpha \beta}=\left[\frac{1}{\left(1+\lambda_{1}\right)\left(1+\lambda_{2}\right)\left(1+\lambda_{3}\right)}\right] \hat{c}_{\alpha \beta} .
$$


Equation (10.27) can now be written

$$
e_{\beta}=\sum_{\alpha=1}^{3} c_{\beta \alpha} T_{\alpha}+\lambda_{\beta}
$$

where $C_{B \alpha}$ is a matrix of temperature-dependent materlal modull defined by

$$
c_{\beta \alpha}=\frac{v_{1}}{\left(I+\lambda_{\alpha}\right)}\left(\tilde{c}_{\alpha \beta}\right)^{-1}
$$

It 18 interesting to note the similarity between the constitutive equation (10.29) and the stress-strain relation from linear thermoelasticlty given by

$$
e_{\beta}=\sum_{\alpha=1}^{3} B_{B \alpha} T_{\alpha}+a_{\beta}\left(\theta-\theta_{0}\right)
$$

where $B_{B \alpha}$ is a symetric matrix of material constants and $a_{\beta} 18$ a constant known as the coefficient of thermal expansion in the direction $B$. It is easy to see that equation (10.29). reduces to (10.30) when the thermal strains are seall. However, in order to obtain an equation which more accurately predicts the behavior of materials oubject to large temperature changes it has been the usual practice to assume (without an analys1s of the approximations 1nvolved) that the material "constants" in (10.31) are functions of temperature. Bquations (10.29) and (10.30) show that, in the general case, this generallzation of the Iinear equation (10.31) is not correct. Because the matrlx $\left(\tilde{c}_{\alpha \beta}\right)^{-1}$ is symetric, equation (10.30) shows that $C_{\text {Br }}$ cannot be symetric unless the thermal expansion 1s 18otroplc. In addition, equation (10.30) shows that the elast1c modull should depend Iinearly upon the inelastic volume otrain $v_{1}$. For example, if the local 
Inelastic volume doubles, the elastic stiffness constants should be reduced by balf. With these differences in mind, we conclude that the practice of allowing the material constants in the constitutive equation of Iinear thermoelasticlty to depend on temperature represents a valld generalization of (10.31) provided the inelastic rolume change is zero and the thermal expansion 18 isotropic. However, whenever the thermal expansion 1s large and anlsotropic or the inelastic volume change is olgniflcant the usual form is insufficlent. When the thermal expansion is amal, the effect of anisotropy on the symetry of the compliance matrix can be neglected.

XI. Sumanary

We have presented a conslotent mathematical theory for describing the large deformation of miterials exhlbiting elastic and riscoplastic behavior. This theory represents a general mathematical framework upon which theorles of the behavior of particular materials can be built. The equations have been presented in a form that guarantees that the second law of thermodynamics and the requirement that the material response be observer Invariant are autamatically satiofied. Th1s ensures that these fundamental principles w1ll never be Inadvertantly volated. Although the development of a general Invarlant theory is necessartly more complex than simply making ad hoc assumptions about a materialis behavior, the oubsequent formulation of particular theorles within the framework of the general theory 18 considerahly almplified. Prom a mechanlcal standpolnt, the fundamental equations which bave been derived are the stress relation

$$
\underline{L}^{*}=\rho \underline{u}_{e}\left(\frac{\partial t}{\partial J_{e}}\right)^{T}
$$


which characterizes the elsstic response of the material, and the inelastic straln rate equation

$$
\Sigma_{1}=\mathscr{H}\left(\hat{A}, \mathrm{u}_{1}, \theta, \sigma_{1}, \ldots, \xi_{1}, \ldots\right)
$$

whlch characterizes the 1nelastic behavior. The elastic behavlor of the material is determined by the form of the free-energy function $t^{-}$In other words, Instead of having elastic constants, a nonlinear elastlc material. is defined by 1 ts energy function t. "We can choose to be any function that 18 appropriate for our analysis, and in 80 dolng, describe a particular elastic material. In Section $X$ a form of the function 18 derived which 18 partlcularly appropriate for irrotational deformations of materials subject to large Inelastic and thermal expansion strains and accompanled by small stress-induced strains. When thls function is substituted into the stress relation given above we obta1n

$$
T_{\alpha}=p\left(\hat{U}_{e}\right)_{\alpha} \sum_{\beta=1}^{3} b_{\alpha \beta}\left[\left(U_{e}\right)_{\beta}-1-\lambda_{B}\right]
$$

for the thermolastic stress-stralo relation. This equation can be Ilnearized further to obtaln

$$
e_{\beta}=\sum_{\alpha=1}^{3} c_{B \alpha} T_{\alpha}+\lambda_{\beta}(\theta)
$$

where

$$
c_{\beta \alpha}=\frac{v_{1}}{\left(1+\lambda_{\alpha}\right)}\left(b_{\alpha \beta}\right)^{-1}
$$


At this time we have farmulated the theory and considered one possible application. We have not explored all of the implications and possible applications of the theory. For example; it should be practical to derive a free-energy function sultable; for describing the thermolastic response of metals undergolng general large three-dimensional inelastic deformation. In addition, the implications of the Inelastic strain rate equations have not been fully explored. It 18 possible that by using an inelastic strain rate equation such as the one given above we could arrive at a more productive mathematical structure for describing creep deformation. 
References

(1) R. Hil1, "The Mathematical Theory of Plasticity," Oxford: Clarenden Press, 1950.

(2) A. Mendelson, "Plasticity: Theory and Application, "Macmillan, New York 1968.

(3) E. H. Lee and D. T. Liu, "Tinite-Strain Elastic-Plastic Theory with Application to Plane Wave Analysis," J. Appl. Phys. 38, 19-27 (19.67).

(4) A. E. Green, and P. M. Naghd1, "A General Theory of, an Elastic-Plastic Continuum," Arch, Rational Mech. Anal, 18, 251 (1965).

(5) E. H. Lee, "Elastic-Plastic Deformation at Finite Strains," J. Apple Mech, 36, 1 (1969).

(6) F. Sideroff, "The Geometrical Concept of Intermediate Configuration and Elastic-Plastic Finite Strain," Arch, Mech, 16, 127 (1973).

(7) $M_{0}$ Kleiber, "Kinematics of Deformation Processes in Materials Subjected to Finite E1astic-Plastic Strains;" Int. J. Engng, Sc1, 13, 513-525 (1975).

(8) I. B. Freund, "Constitutive Equations for Elastic-Plastic Materials at Finite Strain," Int, J. Solids Structures, 6, 1193-1209 (1970).

(9) J. Kratochvi1, "Finite-Strain Theory of Inelastic Behavior of Crystalline Solids," in "Symposium on Foundations of Plastic1ty," A. Sawczuk ed., Noordhoff International, Leyden, (1972).

(10) B. D. Coleman and W. Noll, "The Thermodynamics of Elastic Materials with Heat Conduction and V18cosity," Arch. Rational Mech. Anal., 13, 167-177 (1963).

(11) C. Traesdell and $w$. Noll, "The Nonlinear Fleld Theorles of Mechanics," in "Encyclopedia of Physics," Vol. III/3, Springer-Verlag, New York (1965).

(12) W. Nol1, "On The Continuity of Solid and Fluid States, J, Rational Mech, Anal., 4, 3-81 (1955).

(13) W. Weber, "Uber dié Elastizitat Fester Korper," Annalen der Physik und Chemie, "Second Series, 54, 1-18 (1841).

(14) C. Truesdell, "A Theorem on the Isotropy Groups of a Hyperelastic Material," in "Proc. Nat. Acad. Sc1.," 52, $1081-1083$ (1964).

(15) A. E. Green and W. Zerna, "Theoretical Elasticity," 2d ed., Oxford University Pres8, London (1968). 
(16) J. B. Newman, J. F. Glovengo, and L. P. Comden, "The CYGRO-4 Fuel Rod Analysis Cnmputer Program," WAPD-TM-1300, July 1977.

QU.S. GOVERNMENT PRINTING OFFICE: $1980 / 703-014 / 22$ 